\title{
DIFERENTES AMBIENTES E OSMOCOTE NA PRODUÇÃO DE MUDAS DE TAMARINDEIRO (Tamarindus indica)
}

\author{
Different ambient and Osmocote ${ }^{\circledR}$ for growth of tamarind (Tamarindus indica) \\ fruits seedlings
}

\author{
Vander Mendonça ${ }^{1}$, Nildo Antônio Arruda de Abreu², Henrique Antunes de Souza ${ }^{3}$, \\ Glauco Antônio Teixeira ${ }^{3}$, Oscar Mariano Hafle², José Darlan Ramos ${ }^{4}$
}

\begin{abstract}
RESUMO
Objetivou-se com este trabalho avaliar os efeitos de diferentes ambientes e doses de Osmocote ${ }^{\circledR}$ na produção de mudas de tamarindeiro (Tamarindus indica L). Um experimento foi instalado no Pomar da Universidade Federal de Lavras-MG, empregandose delineamento experimental em blocos casualizados, em esquema fatorial 3 x 4, com quatro repetições e cinco plantas por parcela. Os tratamentos se constituíram dos diferentes ambientes de formação de mudas (casa de vegetação, telado e a céu aberto) e de quatro doses de Osmocote ${ }^{\circledR}: 0 ; 3 ; 6$ e $9 \mathrm{~kg} \mathrm{~m}^{-3}$ de substrato. Avaliaram-se a altura da muda (cm), comprimento da raiz (cm), número de folhas/ planta, matéria seca da parte aérea $(\mathrm{g})$, matéria seca da raiz $(\mathrm{g})$ e a matéria seca total $(\mathrm{g})$. Os resultados demonstraram que o Osmocote ${ }^{\circledR}$ $(15-10-10)$ pode ser recomendado para a formação de mudas de tamarindo, em doses de até $6,0 \mathrm{~kg} \cdot \mathrm{m}^{-3}$. $\mathrm{O}$ ambiente a céu aberto foi o que proporcionou melhor qualidade às mudas.
\end{abstract}

Termos para indexação: Leguminosae, tamarindo, nutrição, propagação.

\begin{abstract}
This work aimed to evaluate the effect of ambient and Osmocote ${ }^{\circledR}(15-10-10)$ doses on the production of tamarind fruits seedlings. An experiment was carried out in a nursery at Universidade Federal de Lavras, Brazil, arranged in a randomized complete block outline and a $3 \times 4$ factorial scheme, with four replications and five plants per plot. The treatments were constituted by

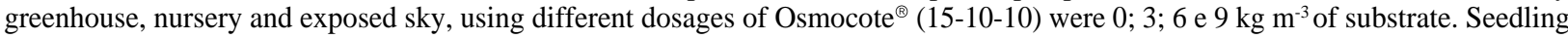
growth, height, number of leaves, aerial part, root and total dry matter were evaluated. The results showed that of Osmocote ${ }^{\circledR}$ (1510-10) can be recommended for the formation of tamarind seedlings, at doses of until $6 \mathrm{~kg} \mathrm{~m}^{-3}$. Sky exposing was the one which provided better quality to the seedlings.
\end{abstract}

Index terms: Leguminosae, tamarind, nutrition, propagation

(Recebido em 22 de junho de 2006 e aprovado em 28 de agosto de 2007)

\section{INTRODUÇÃO}

O tamarindeiro (Tamarindus indica) é originário da África tropical, de onde se dispersou por todas as regiões tropicais. É uma frutífera bastante decorativa, podendo chegar aos $25 \mathrm{~m}$ de altura. Seu fruto é uma vagem alongada, com 5 a $15 \mathrm{~cm}$ de comprimento, com casca pardo-escura, lenhosa e quebradiça, contendo 3 a 8 sementes envolvidas por uma polpa parda e ácida (DONADIO et al., 1988).

A planta se desenvolve bem nos mais diferentes tipos de solos, mesmo nos mais degradados. Contudo, o período sem produção dura por volta de 12 anos e o tamarindeiro sobrevive por um século ou mais (PATHAK et al., 1991).
Segundo o IPA (1997), as mudas de tamarindo são formadas a partir de sementes que são lançadas ao solo a $2-3 \mathrm{~cm}$ de profundidade em linhas de $15 \mathrm{~cm}$ sobre canteiros de terra constituído de mistura de terriço ( 3 partes) e esterco de curral bem curtido (1 parte). Com $10 \mathrm{~cm}$ de altura, as mudas vigorosas são transportadas para sacos de polietileno com $18 \mathrm{~cm}$ x $30 \mathrm{~cm}$, alcançando $25 \mathrm{~cm}$ de altura a muda estará apta ao transplantio.

Um dos maiores problemas encontrados nos viveiros de plantas frutíferas é o alto custo de produção das mudas. Isso se deve, em parte, ao tempo de desenvolvimento das plantas e, conseqüentemente, do elevado gasto com insumos (defensivos e fertilizantes), mão de obra e equipamentos.

\footnotetext{
Doutor, Professor Adjunto - Ciências Vegetais/CV - Universidade Federal Rural do Semi-Árido/UFERSA - BR 110, Km 47 - Presidente Costa e Silva 59625-900 - Mossoró, RN - vander@ufersa.edu.br

2Engenheiro Agrônomos, Mestres - Departamento de Agricultura/DAG - Universidade Federal de Lavras/UFLA - Cx. P. 3037 - $37200-000$ - Lavras, MG vander@ufersa.edu.br; hafleom@yahoo.com.br

${ }^{3}$ Engenheiro Agrônomo - Departamento de Agricultura/DAG - Universidade Federal de Lavras/UFLA - Cx. P. 3037 - $37200-000$ - Lavras, MG henrique.antuness@yahoo.com.br; glaucoufla@yahoo.com.br

${ }^{4}$ Engenheiro Agrônomo, Doutor, Professor - Departamento de Agricultura/DAG - Universidade Federal de Lavras/UFLA - Cx. P. 3037 - $37200-000$ -

Lavras, MG - darlan@ufla.br
} 
Neste contexto, a prática de adubações, além de se constituir num fator indispensável para o desenvolvimento das mudas, acelera consideravelmente o crescimento das mesmas, reduzindo os custos de produção. A eficiência das adubações, principalmente daquelas realizadas em cobertura, depende basicamente das doses e fontes dos adubos utilizados, da capacidade de troca catiônica e das características físicas do substrato (SGARBI et al., 1999).

Uma das alternativas para aumentar a eficiência dessas adubações seria a realização de maior parcelamento, principalmente quando se trata do nitrogênio. Porém, esta prática apresenta um aumento significativo no custo operacional. Outra alternativa seria a utilização de fontes que apresentam uma liberação mais lenta ou controlada dos nutrientes. Um exemplo deste tipo de fertilizante é o Osmocote $^{\circledR}$ (SGARBI et al., 1999).

O Osmocote ${ }^{\circledR}(15-10-10)$ é um fertilizante com tempo de liberação em torno de 4 a 6 meses que, além de conter $15 \%$ de $\mathrm{N}, 10 \%$ de $\mathrm{P}_{2} \mathrm{O}_{5}$ e $10 \%$ de $\mathrm{K}_{2} \mathrm{O}$, apresenta ainda em sua formulação $3,8 \%$ de $\mathrm{Ca}, 1,5 \%$ de $\mathrm{Mg}, 3,0 \%$ de $\mathrm{S}, 0,02 \%$ de $\mathrm{B}, 0,05 \%$ de $\mathrm{Cu}, 0,5 \%$ de $\mathrm{Fe}, 0,1 \%$ de $\mathrm{Mn}, 0,004 \%$ de $\mathrm{Mo}$ e $0,05 \%$ de $\mathrm{Zn}$. Pelo fato do Osmocote ${ }^{\circledR}$ permitir a disponibilidade contínua de nutrientes para as mudas, durante um maior tempo, existe menor possibilidade de ocorrer deficiência de nutrientes durante o período de formação das mudas, o que dispensaria aplicações parceladas de outras fontes, reduzindo assim os custos operacionais na formação da muda. É um fertilizante indicado tanto para produção de mudas de algumas frutíferas (MENDONÇA et al., 2004a,b,c) como ornamentais e oleráceas (BRITTON et al., 1998; PILL \& BISCHOFF, 1998).

Ambientes protegidos, como casa-de-vegetação e telados, são os locais mais indicados por serem mais protegidos de ataque de pragas e doenças. Entretanto, não foram encontradas referências de trabalhos com a cultura do tamarindo que comparem as qualidades de mudas formadas nesses diferentes ambientes.

Objetivou-se com este trabalho avaliar o efeito de diferentes ambientes e doses de Osmocote ${ }^{\circledR}$ na produção de mudas de tamarindeiro.

\section{MATERIAL E MÉTODOS}

O experimento foi conduzido em viveiro telado, com sombrite $50 \%$ no pomar didático da Universidade Federal de Lavras-UFLA, município de Lavras-MG, no período de dezembro de 2004 a abril de 2005.

As sementes do tamarindeiro, provenientes de plantas matrizes do pomar da Escola Agrotécnia Federal de Souza-PB, foram semeadas em sacos de polietileno com capacidade de 2,5 L. Na semeadura, colocaram-se duas sementes por recipiente e, dez dias após a germinação, fez- se um desbaste, deixando apenas a muda mais vigorosa no recipiente. $\mathrm{O}$ substrato utilizado para enchimento dos sacos de polietileno foi constituído da mistura de terra, esterco de curral curtido e areia lavada na proporção de 3:2:1(v/v).

$\mathrm{O}$ delineamento experimental utilizado foi em blocos casualizados, em esquema fatorial 3 x 4, com quatro repetições e cinco plantas por parcela. Os tratamentos consistiram na combinação de diferentes ambientes de formação de mudas (casa de vegetação, telado e a céu aberto) e de quatro doses de Osmocote $^{\circledR}\left(0 ; 3 ; 6\right.$ e $9 \mathrm{~kg} \mathrm{~m}^{-3}$ de substrato).

Os tratos culturais utilizados foram a irrigação, feita de manhã e à tarde utilizando-se regador manual; controles de pragas e doenças e a retirada manual das plantas daninhas.

As características avaliadas, aos 150 dias após a semeadura, foram a altura da muda $(\mathrm{cm})$, medida a partir do colo até a gema apical; comprimento da raiz $(\mathrm{cm})$, medida a partir do colo até a extremidade da raiz e número de folha/ planta. Posteriormente as partes foram colocadas em estufa à temperatura de $65^{\circ} \mathrm{C}$, até atingir peso constante. Após isso, foram efetuadas pesagens, encontrando-se assim a matéria seca da parte aérea e matéria seca da raiz e com a soma das duas encontrou-se a matéria seca total

Os resultados foram submetidos à análise de variância, e as médias dos dados qualitativos comparadas pelo teste de Tukey, a 5\% de probabilidade, e os dados quantitativos pela análise de regressão (GOMES, 2000). As análises foram realizadas pelo programa computacional Sistema para Análise de Variância - SISVAR (FERREIRA, 2000).

\section{RESULTADOS E DISCUSSÕES}

Pela Tabela 1 verifica-se que a altura, matéria seca da parte aérea e matéria seca total foram influenciadas pela interação entre os diferentes ambientes e as doses de Osmocote ${ }^{\circledR}$ empregadas, enquanto para o número de folhas houve efeito dos dois fatores isoladamente e a matéria seca da raiz foi influenciada apenas pelos tratamentos com Osmocote ${ }^{\circledR}$. Não houve efeito de nenhum tratamento sobre o comprimento da raiz.

A altura da muda de tamarindo apresentou um comportamento quadrático em relação as doses de Osmocote ${ }^{\circledR}$ sendo o ponto de máxima altura encontrado, através da derivada da equação, de $70,0 \mathrm{~cm}$ na dose 5,17 $\mathrm{kg} \cdot \mathrm{m}^{-3}$ e a menor altura foi de $25,72 \mathrm{~cm}$ quando não foi utilizado o fertilizante (Figura 1). Trabalhando com este mesmo fertilizante Mendonça et al. (2004b) observaram em mudas de maracujazeiro-amarelo que as dose que promoveu maior altura das mudas $(54,95 \mathrm{~cm})$ foi também de $5,17 \mathrm{~kg} \cdot \mathrm{m}^{-3}$. Também testando este fertilizante em mudas de mamoeiro 'Formosa', Mendonça et al. (2004a), constataram que a dose de $12 \mathrm{~kg} . \mathrm{m}^{-3}$ foi a que proporcionou melhor resposta para a altura das mudas $(24,22 \mathrm{~cm})$. 
Tabela 1 - Resultado da análise de variância para altura, comprimento da raiz, número de folhas, matéria seca da parte aérea, da raiz e total, em função dos diferentes ambientes $(\mathrm{A})$ e doses de Osmocote ${ }^{\circledR}(\mathrm{O})$ na produção de mudas de tamarindo. Lavras, MG, 2005.

\begin{tabular}{cccccccc}
\hline $\begin{array}{c}\text { Fontes de } \\
\text { Variação }\end{array}$ & GL & $\begin{array}{c}\text { Altura } \\
(\mathrm{cm})\end{array}$ & $\begin{array}{c}\text { Comprimento } \\
\text { da raiz }(\mathrm{cm})\end{array}$ & $\begin{array}{l}\mathrm{N}^{\circ} \text {. de } \\
\text { folhas }\end{array}$ & $\begin{array}{c}\text { Matéria seca da } \\
\text { parte aérea }(\mathrm{g})\end{array}$ & $\begin{array}{c}\text { Matéria seca } \\
\text { da raiz }(\mathrm{g})\end{array}$ & $\begin{array}{c}\text { Matéria seca } \\
\text { total }(\mathrm{g})\end{array}$ \\
\hline Ambiente $(\mathrm{A})$ & 2 & $2113,29^{* *}$ & $164,9^{\mathrm{ns}}$ & $77,14^{*}$ & $52,14^{* *}$ & $2,58^{\mathrm{ns}}$ & $77,77^{* *}$ \\
Osmocote $^{\otimes}(\mathrm{O})$ & 3 & $626,51^{* *}$ & $139,16^{\mathrm{ns}}$ & $56,71^{*}$ & $21,71^{*}$ & $6,95^{* *}$ & $42,16^{* *}$ \\
$\mathrm{~A}$ x O & 6 & $186,10^{*}$ & $125,77^{\mathrm{ns}}$ & $28,80^{\mathrm{ns}}$ & $32,79^{* *}$ & $1,002^{\mathrm{ns}}$ & $43,19^{* *}$ \\
Bloco & 3 & 186,45 & 411,34 & 56,49 & 5,27 & 1,04 & 7,32 \\
Resíduo & 33 & 62,54 & 56,04 & 19,93 & 4,20 & 0,96 & 4,22 \\
\hline $\mathrm{CV}(\%)$ & & 17,11 & 30,77 & 22,74 & 35,77 & 45,58 & 26,49 \\
\hline
\end{tabular}

**Significativo a $1 \%$ de probabilidade, pelo teste F; $*$ Significativo a $5 \%$ de probabilidade, pelo teste $\mathrm{F}$. ns-Não significativo.

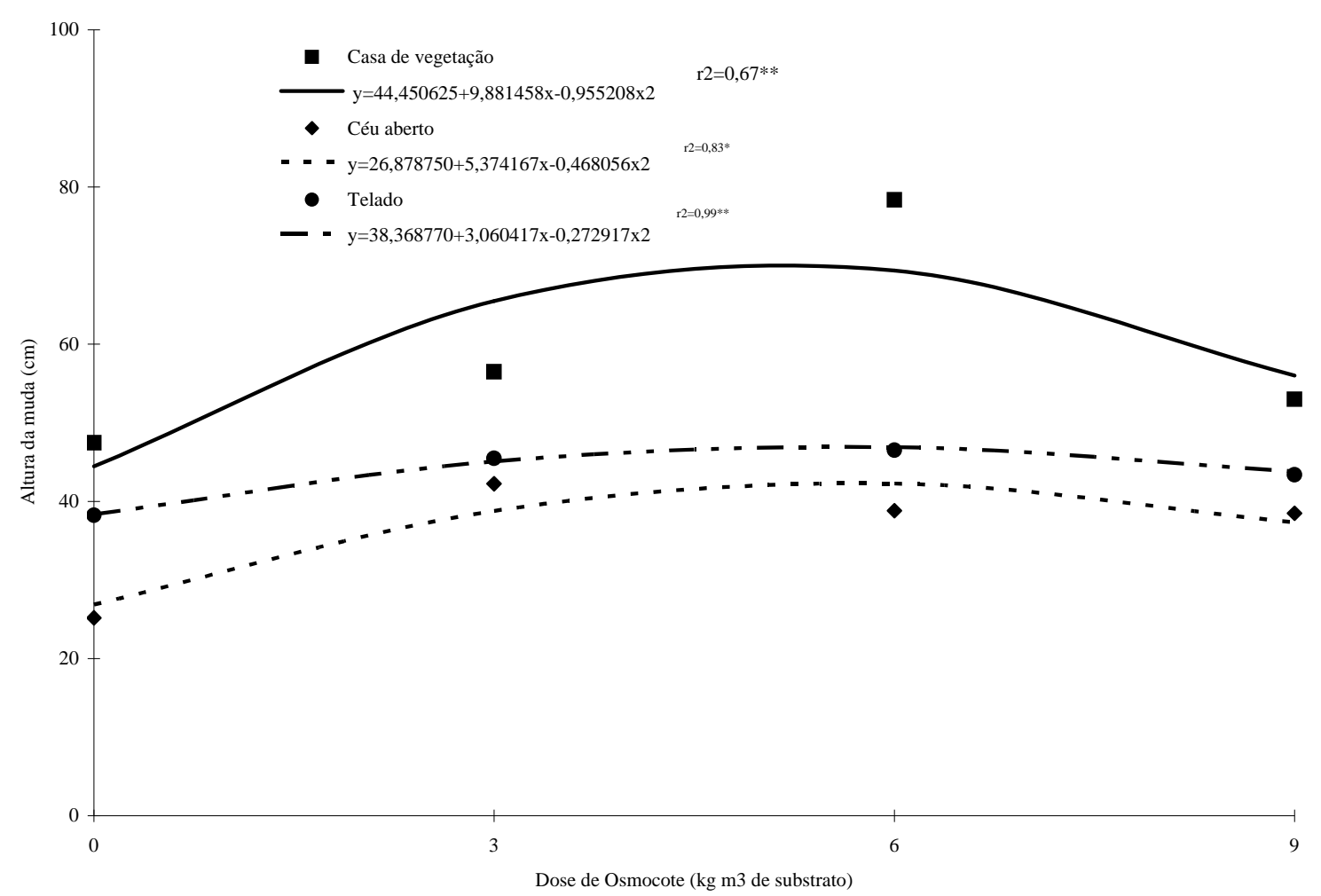

Figura 1 -Altura de mudas de tamarindo em função da aplicação de Osmocote e diferentes ambientes. Lavras-MG, 2005.

Para o número de folhas a melhor dose do fertilizante foi de $5,17 \mathrm{~kg} \cdot \mathrm{m}^{-3}$ o qual proporcionou em média 21 folhas por mudas (Figura 2). Em relação ao ambiente, as melhores respostas para o número de folhas (21) foram obtidas a céu aberto e em telado (Figura 3).

A melhor resposta da matéria seca da parte aérea $(11,0 \mathrm{~g})$ foi obtida na dose de $8,89 \mathrm{~kg} \cdot \mathrm{m}^{-3}$ do fertilizante no ambiente a céu aberto, valor este bem superior ao observado neste mesmo ambiente sem a utilização deste fertilizante (2,21 g) (Figura 4).

Para a matéria seca da raiz (Figura 5) a melhor resposta $(2,91 \mathrm{~g})$ foi obtida quando utilizou-se a dose de $4,28 \mathrm{~kg} \cdot \mathrm{m}^{-3}$ do fertilizante. Já em relação a matéria seca total, observou-se que o ambiente a céu aberto e o fertilizante na dose de $6,80 \mathrm{~kg} \cdot \mathrm{m}^{-3}$ foi a combinação que promoveu a melhor resposta para esta variável (13,56 g) (Figura 6). 


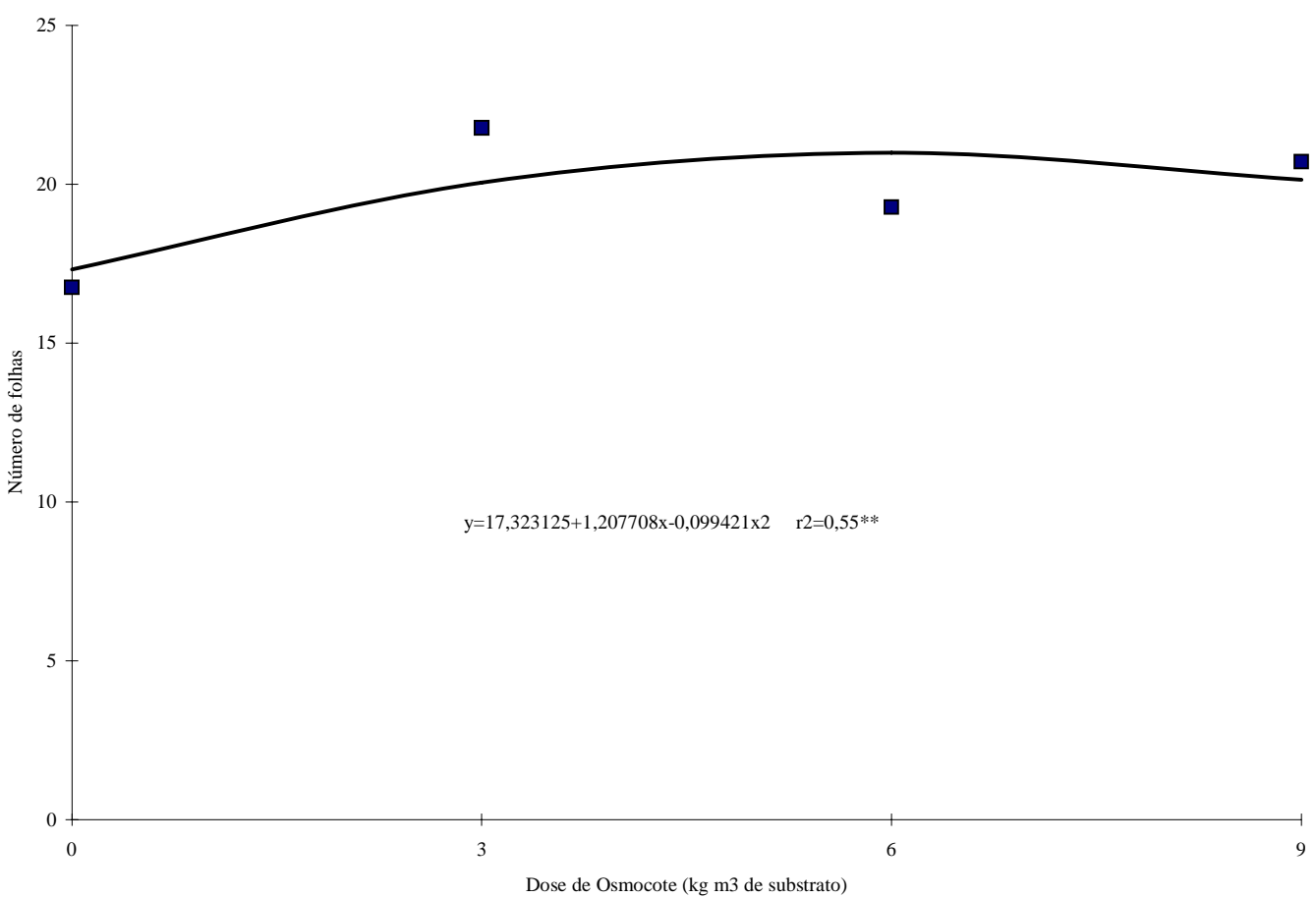

Figura 2 - Número de folhas de mudas de tamarindo em função da aplicação de Osmocote. Lavras-MG, 2005.

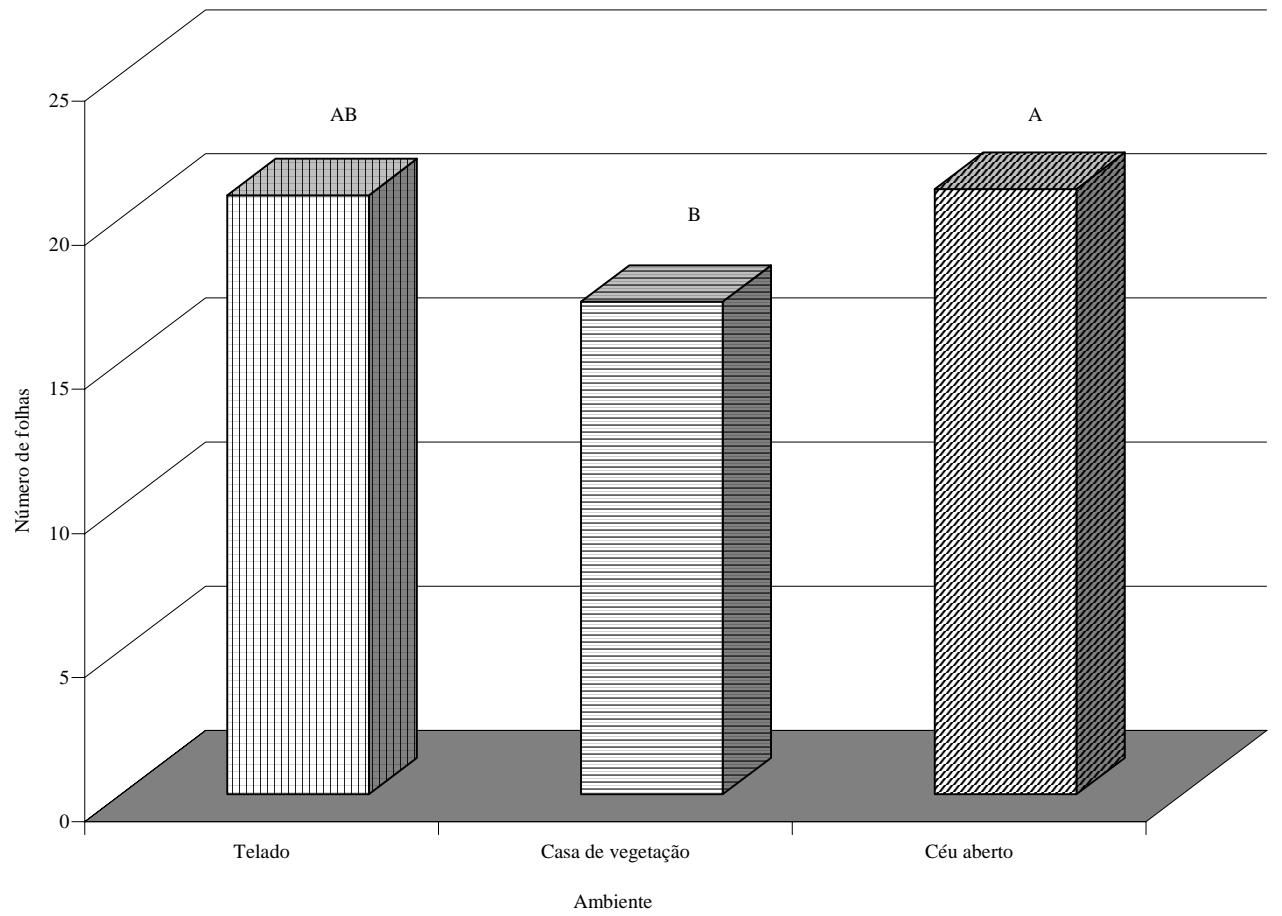

Figura 3 - Número de folhas de mudas de tamarindo em função dos ambientes. Letras indicam diferenças significativas pelo teste de Tukey a 5\%. Lavras-MG, 2005.

Ciênc. agrotec., Lavras, v. 32, n. 2, p. 391-397, mar./abr., 2008 


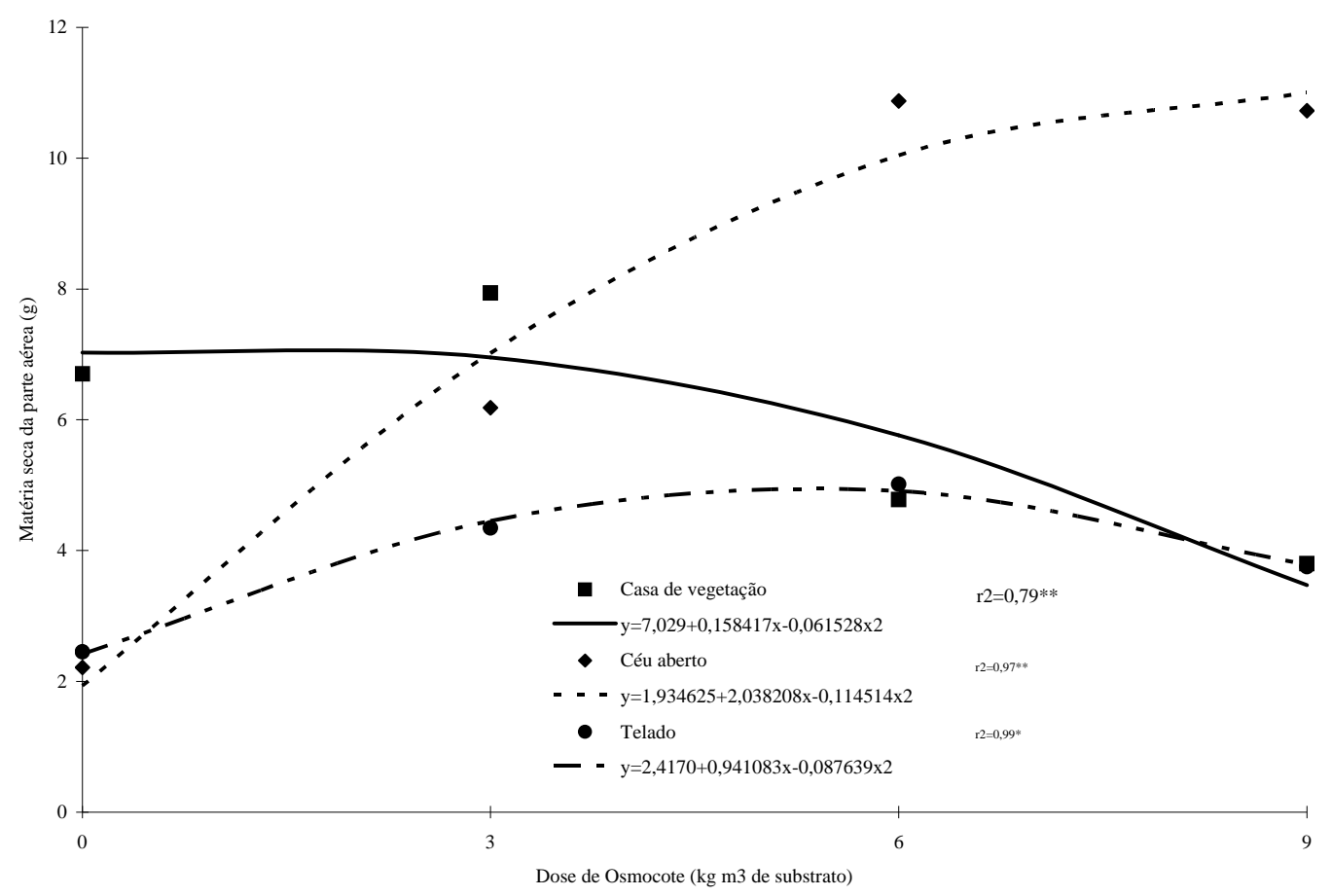

Figura 4 - Matéria seca da parte aérea de mudas de tamarindo em função da aplicação de Osmocote e diferentes ambientes. Lavras-MG, 2005.

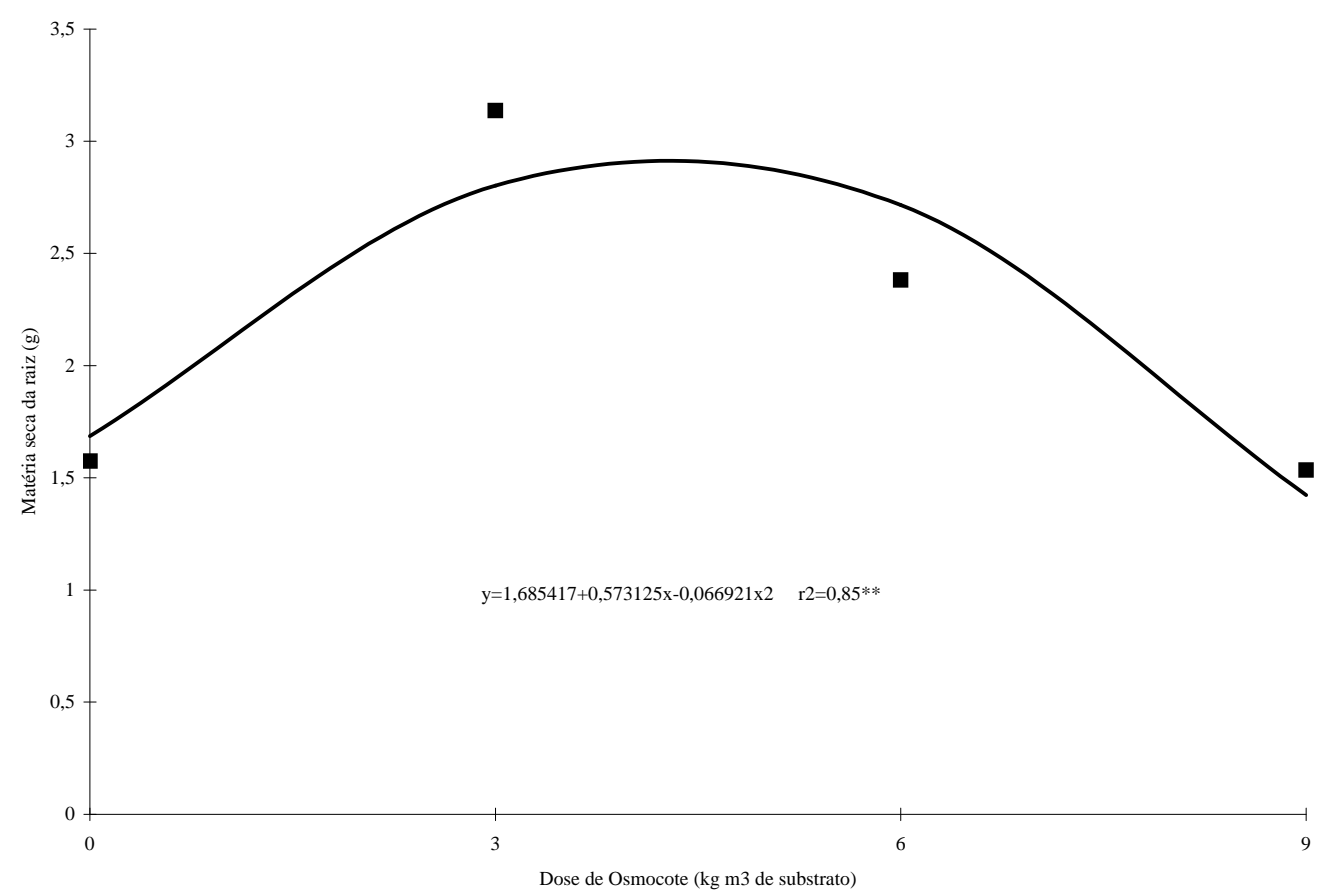

Figura 5 - Matéria seca da raiz de mudas de tamarindo em função da aplicação de Osmocote. Lavras-MG, 2005. 


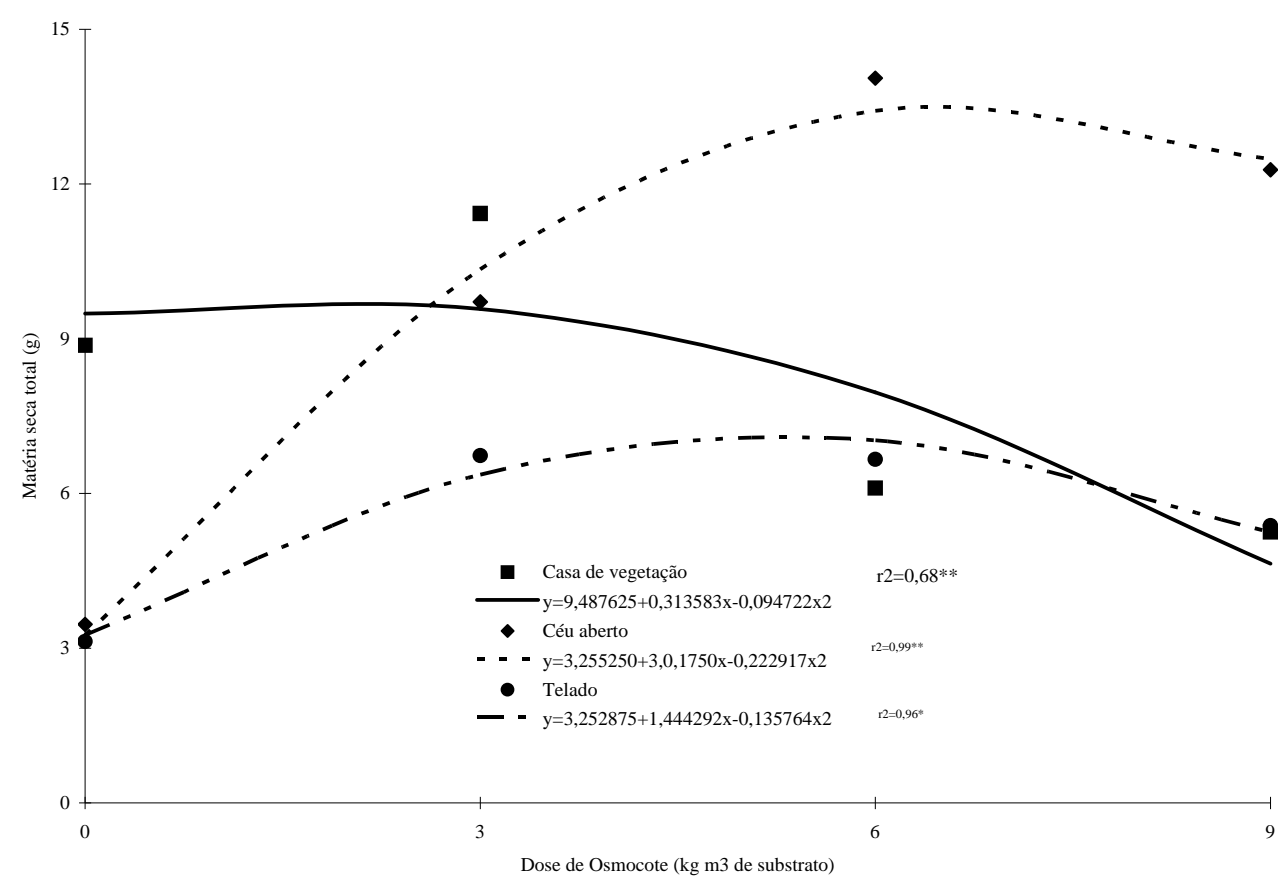

Figura 6 - Matéria seca total de mudas de tamarindo em função da aplicação de Osmocote e diferentes ambientes. Lavras-MG, 2005.

Existem poucos trabalhos na literatura com relação à cultura do tamarindo, talvez por ser ainda uma frutífera pouco conhecida entre os brasileiros. Entretanto, na região nordeste do Brasil esta frutífera é relativamente bem conhecida.

A utilização do Osmocote ${ }^{\circledR}$ está sendo realizada com sucesso na produção de mudas de outras espécies. Na produção de mudas de maracujazeiro-amarelo, Pereira et al. (2000), testando diferentes doses deste fertilizante e substratos, concluíram que para substratos a base de areia, vermiculita e esterco de curral curtido na proporção de 1:1:1 $\mathrm{v} / \mathrm{v}$, a dose de Osmocote ${ }^{\circledR}$ recomendada é de $8 \mathrm{~kg} \cdot \mathrm{m}^{-3} \mathrm{e}$ substratos a base de solo e esterco na proporção de $2: 1 \mathrm{v} / \mathrm{v}$ a dose recomendada é de 4,5 kg.m ${ }^{-3}$. Em mudas de maracujazeiro-doce, Mendonça et al. (2004c) concluíram que o Osmocote ${ }^{\circledR}(15-10-10)$ na dose de $6 \mathrm{~kg} \cdot \mathrm{m}^{-3}$ em substrato a base de esterco de curral, casca de café, carvão vegetal, areia e solo na proporção de 1:1:1:1:2 v/v ou em substratos a base de esterco de curral, casca de arroz carbonizada, casa de café, areia e solo na proporção de 1:1:1:1:2 foram as combinações que promoveram melhor qualidade na produção de mudas do maracujazeiro-doce.

$\mathrm{Na}$ formação de mudas de cafeeiro, Andrade Neto et al. (1999) observaram que a utilização de Osmocote ${ }^{\circledR}$ na fórmula 15-10-10 de NPK com micronutrientes foi superior à mistura de cloreto de potássio e superfosfato simples.

Um dos benefícios do Osmocote ${ }^{\circledR}$ em relação aos outro fertilizantes é a liberação lenta, o que proporciona um melhor aproveitamento dos nutrientes pela muda durante sua formação. Huett (1997) comprovou esta eficiência do Osmocote ${ }^{\circledR}$ observando que a lixiviação de nutrientes contidos neste fertilizante foi menor quando comparada aos adubos solúveis.

Talvez por ser uma frutífera classificada com tropical ou subtropical, sendo assim mais resistentes às condições adversas de temperatura e umidade, o tamarindo tenha maior tolerância e/ou exigência a ambientes mais "rústicos", o que justificaria o ambiente a céu aberto ter proporcionado melhores condições para a formação das mudas.

\section{CONCLUSÕES}

O Osmocote ${ }^{\circledR}(15-10-10)$ pode ser recomendado para a formação de mudas de tamarindeiro, sendo a dose em torno de até $6,0 \mathrm{~kg} . \mathrm{m}^{-3}$ as que promoveram os melhores resultados.

$\mathrm{O}$ ambiente a céu aberto e em telado foram os que proporcionaram as melhores condições para a formação das mudas de tamarindeiro.

\section{REFERÊNCIAS BIBLIOGRÁFICAS}

ANDRADE NETO, A. de; MENDES, A. N. G.; GUIMARÃES, P. T. G. Avaliação de substratos alternativos e tipos de adubação para a produção de mudas de cafeeiro (Coffea arabida L.) em tubetes. Ciências e Agrotecnologia, Lavras, v. 23, p. 270-280, 1999. 
BRITTON, W.; HOLCOMB, E. J.; BEATTIE, D. J. Selecting the optimum slow-release fertilizer of five cultivars of tissue-cultured Hosta. HortTechnology, Alexandria, v. 8, p. 203-206, 1998.

DONADIO, L. C.; NACHTIGAL, J. C.; SACRAMENTO, C. K. do. Frutas exóticas. Jaboticabal: Funep, 1988. 279 p.

FERREIRA, D. F. Análise estatística por meio do SISVAR (Sistema para Análise de Variância) para Windows versão 4.0. In: REUNIÃO ANUAL DA REGIÃO BRASILEIRA DA SOCIEDADE INTERNACIONAL DE BIOMETRIA, 45., 2000, São Carlos. Anais... São Carlos: UFSCar, 2000. p. 255-258.

GOMES, F. P. Curso de estatística experimental. 14. ed. Piracicaba: USP, 2000. 477 p.

HUETT, O. O. Fertilizer use efficienty by containerised nursery plants: 2. nutrient leaching. Australian Journal Agricultural Research, Victoria, v. 48, p. 251-258, 1997.

IPA. Empresa Pernambucana de Pesquisa Agropecuária. Recomendações para o cultivo de frutas tropicais. Recife, 1997. Disponível em: <http://www.bahia.ba.gov.br/seagri/ Tamarindo.htm>. Acesso em: 2 dez. 2005.

MENDONÇA, V.; RAMOS, J. D.; DANTAS, D. J.; MARTINS, P. P. C.; GONTIJO, T. C. A.; PIO, R. Efeito de doses de Osmocote e dois tipos de substratos no crescimento de mudas do mamoeiro 'Formosa'. Ceres, Viçosa, v. 51, n. 296, p. 467-476, 2004a.

MENDONÇA, V.; RAMOS, J. D.; GONTIJO, T. C. A.; MARTINS, P. P. C.; DANTAS, D. J.; PIO, R.; ABREU, N. A.
A. Osmocote e substratos alternativos na produção de mudas de maracujazeiro-amarelo. Ciências e Agrotecnologia, Lavras, v. 23, n. 4, p. 799-806, 2004 b.

MENDONÇA, V.; RAMOS, J. D.; PIO, R.; GONTIJO, T. C. A.; DANTAS, D. J. MARTINS, P. P. C. Formação de mudas de maracujazeiro-doce com uso de fertilizante Osmocote e misturas alternativas de substratos. Ceres, Viçosa, v. 51, n. 295 , p. 383-390, 2004c.

PATHAK, R. K.; OJHA, C. M.; DWIVEDI, R. Adopt patchbudding for quicker multiplication in tamarind. Horticulture, [S.1.], v. 36, n. 3, p. 17, 1991.

PEREIRA, W. E.; LIMA, S. F. de; PAULA, L. B. de; ALVAREZ, V. H. Crescimento e composição mineral de mudas de maracujazeiro em função de doses de Osmocote em dois tipos de substratos. Revista Ceres, Viçosa, v. 47, n. 271 , p. $311-324,2000$

PILL, W. G.; BISCHOFF, D. J. Resin-coated, controlledrelease fertilizer as a pre plant alternative to nitrogen enrichment of stem core in soilless media containing ground stem core of kenak (Hibiscus cannabinus L.). Journal Horticultural Science \& Biotechnological, [S.1.], v. 73, p. 73-79, 1998.

SGARBI, F.; SILVEIRA, R. V. A.; HIGASHI, E. N.; PAULA, T. A. e; MOREIRA, A.; RIBEIRO, F. A. Influencia da aplicação de fertilizante de liberação controlada na produção de mudas de um clone de Eucalyptus urophylla. In: SIMPÓSIO SOBRE FERTILIZAÇÃO E NUTRIÇÃO FLORESTAL, 2., 1999, Piracicaba. Anais... Piracicaba: IPEFESALQ, 1999. p. 120-125. 